\title{
Exploration and Achievement of the Ways for Resources Integration of Independent Institutes in the Regional Innovation-driven Development
}

\author{
Kequan Feng \\ Lab and Assets Management Office \\ Zhuhai College of Jilin University \\ Zhuhai, China
}

\begin{abstract}
To promote colleges to serve regional innovationdriven development cannot only make it become a power engine to carry out the regional innovation driven development strategy but also becomes a necessary selection to achieve the college transformation and development, independent institute is a newly rising college running mode, and experimental resources are significant to cultivate applied talents, colleges are expected to serve local economic development during talents cultivation, and cooperate with local authorities, enterprises and public institutions so as to establish an interactive mechanism with local innovation-driven development, changing from leading by authorities to actively seeking to serve the society. With experimental resources activated to serve the local economy, college labs will have their construction further upgraded, achieving the integration of experimental resources and local innovation-driven development.
\end{abstract}

Keywords-independent institute; region; innovation driven; integration

\section{INTRODUCTION}

Colleges own a great number of human resources and R\&D achievements, local colleges have also been aware of the mission, transforming from knowledge transfer to knowledge development, from towers of ivory far away for the society to social service stations. With the development of higher education in China, due to national development and talent demands, the authorities have gradually understood the importance of colleges in regional economic development; in the meantime, colleges have known their roles in regional social and economic development. Labs are a key point for talent cultivation in colleges, college labs are teaching bases not only for teaching but also teachers to engage in scientific research, technical innovation and talents cultivation and also an important window to serve social economic development. During the talents cultivation in colleges, we should make full use of experimental resources and improve talents cultivation quality and level so as to better local economy and drive regional innovation-driven development, which play an important role. Acting as the main front to improve regional

Fund Program: 2016 Guangdong Provincial-level Key Platform and Major Scientific Research Program, Name: Study on Ways for Deep Integration between Applied Universities Experimental Resources and Regional Economic Development (2016WQNCX177). innovative culture soft strength, experimental resources in colleges are main forces to talents construction and power for technical innovation. To promote colleges to serve regional innovation-driven development cannot only make it become a power engine to carry out the regional innovation driven development strategy but also becomes a necessary selection to achieve the college transformation and development, here we take Jilin University Zhuhai College as an example.

\section{Status QuO of Regional AND College EXPERIMENTAL RESOURCES}

With the social demand and development of college cultivation modes, the social service of labs in colleges varies in form. Generally speaking, the social service of labs in colleges has three forms:

College-enterprise joint education mode, called sandwich mode, it divides learning into three parts. Part I, cultivate through college labs, make use of instruments and apparatus in labs to complete the learning task of professional courses and professional basic courses, make relevant basic experimental training; Part II, train through enterprises, students are distributed to relevant research labs or factories for practice, whose capabilities will be trained and improved in projects or production; Part III, students return to college labs and select corresponding specialized direction and courses according to the graduation project selected in practice in enterprises, and complete tasks and study in college labs. It helps to improve students' practical capabilities and cultivate engineering applied advanced technical talents for the society. The educational modes where learning and practice are combined and both colleges and enterprises participate are proved applicable and efficient.

Industry-University-Research mode, it is a successful college lab social service form in developed countries, and it is a new mode which is guided by national industrial development layout, supported by national organizations and sectors and based on college labs.

College Technical Park Mode, established in 1951, American "Silicon Valley" was an output of college technical park. In order to guarantee adequate costs, Stanford University created the first technical industry park around the world, 
which had not only brought abundant income but also strengthen the relations between college labs and local industries. After China's reforms and opening up, colleges in the country, based on actual situations of the country, borrowed the mode and created a hi-tech industrial way with Chinese characteristics - hi-tech enterprises run by colleges independently, where technical R\&D labs were set, and enterprises were depended on to develop technical industrial parks. Driven and influenced by college technical industrial parks, industry-university-research cooperation has been launched across the country.

In 2016, Jinwan District, Zhuhai, Guangdong Province greatly carried out the innovation driven development strategy, promoting the innovation driving work from five points such as policy and college resources, there are five colleges in the district, accounting to half of that in the city, which are advantages for innovative development. The district will build college innovation appliance, promote college-enterprise cooperation and set up a public technical service platform. In the meantime, it will further intensify the government-collegeenterprise cooperation, and build an innovative alliance including governments, enterprises and colleges. The district is an important of Zhuhai College Park, owning four colleges such as Guangdong Polytechnic of Science and Technology, Zunyi Medical College, Jilin University Zhuhai College, Zhuhai Institute of Arts and Career and Zhuhai City Polytechnic.

Independent institute is a new rising local college, which is a new thing, and its lab construction is mainly based on that of parent colleges, however, due to the limitation in funds, the lab construction is facing difficulties such as single fund source, so the lab construction shall be aimed at cultivating applied talents. Going with the development and expansion of independent institute, after a decade or more of years of construction, the lab construction has reached certain size with basic functions. After completion of construction in quantity, during the 13th five-year plan, main tasks of labs construction in independent institutes are to improve the quality, intensify internal management, find a way for connotative development, integrate resources, plan scientifically and fully exert the benefits of labs, and labs shall further serve the local economy and provide efficient service for the local economy.

\section{MAIN PROBLEMS}

Main staffs are young in colleges that are in the lack of practice teachers, having little experience in practice, and experimental resources such as instruments and apparatus in labs cannot be fully used, besides, currently all are required to fully connected with the society, and experimental equipment and environment shall be fit for the status quo of enterprises to cultivate applied talents and meet social demands. Though the college labs have their awareness improved in social service, yet it is still insufficient, so the awareness to serve local economy shall be deeply carried out in the lab construction, during the construction, the thought of serving local economy shall be carried out.
IV. MEASURES TO LAUnCH TALENT CULtivation AND SERVE LOCAL ECONOMY UNDER THE INNOVATION DRIVEN DEVELOPMENT

As an independent local college, independent institute shall not only take the mission of talent cultivation, technical innovation but also serve the local economic development. In order to better cultivate quality talents and provide more talents and technical support for the social and economic development, independent institute shall explore and start from the following.

\section{A. Set up an Information Dialogue Mechanism with Local Authorities, Enterprises and Public Institutions}

Independent institute shall make deep surveys at authorities, enterprises and so on to grasp the local social and economic development in all aspects, the demands of authorities, enterprises and public institutions for talents and technologies, consider actual conditions of its own, independent institute shall establish corresponding talent cultivation plans; in the meantime, it shall expose the talent cultivation, lab information resources and technical R\&D to local authorities, enterprises and public institutions. Through the information dialogue mechanism with authorities, enterprises and public institutions, independent institute can regularly make deep discussion and analysis on the regional economic development and college construction, aimed to share resources and information, promoting each other and win-win.

\section{B. Build Continued Education and Talent Cultivation Bases}

Local authorities shall back the talent cultivation of independent institute, improve local human quality and technical culture education, enterprises and public institutions shall cooperate with colleges to build talents exchange and cultivation bases. Build continued education bases in colleges and provide a good platform for the further study and education of employees in enterprises and public institutions and the regional economy. Build college practice bases at enterprises and public institutions and provide a practice platform for college students and teachers. Make use of existing lab resources to serve the local economy, and provide cadre training, accountant qualification exams and national computer skills assessment and so on.

\section{Strengthen Lab Faculty Construction and Set up Talent Flow Mechanism}

Make use of advantageous subjects in colleges and follow what local enterprises need, strengthen talents cultivation and provide talents for the local economic development. It can be done from two points, first, invite engineers and technicians with senior titles and rich experiences from enterprises nearby to instruct practice teaching in college labs, second, send college teachers and theory researchers to participate in technical development and production of enterprises nearby. Through interaction and exchanges, it will push its close communication and contacts with those who have experience in the society to further the practice teaching in colleges and jointly provide excellent talents for the society. 


\section{Exert the Roles of Service Platforms}

In 2010, Jilin University Zhuhai College Chemical and Pharmacy Department Lab was approved as medium and small enterprise bio-medicine service platform by Guangdong Medium and Small Enterprises Bureau, from then on, the platform has been insisting on the direction "Governmentleads, market-orientated, industry-oriented and serve enterprises and share resources, focus on effect". In recent years, the platform has provided services such as sample testing, project cooperation, technical support and employee training for about 100 medium and small enterprises across the country, and established a long term friendly cooperation with each other.

\section{RAISE FUNDS FROM MORE SOURCES FOR LAB CONSTRUCTION AND STRENGTHEN TALENTS TRAINING}

In order to better cultivate talents and serve the local economy, it is urgent to accelerate the lab construction. It will be a great pressure for raising funds, so colleges should expand financing sources through government-college cooperation, college-enterprise cooperation, provide efficient fund guarantee for the lab construction, guarantee the lab construction to start in all aspects, improve lab functions. Besides, if it can raise funds from such sources, it guarantees that the labs established by the local and colleges are to meet the local needs of economic development, also meeting the needs of teaching and scientific research of labs, meeting the need of talent cultivation and achieving the effect of mutual benefits from labs.

\section{OPTIMIZE RESOURCE ALLOCATION AND PROVIDE A SOUND ENVIRONMENT FOR TALENT CULTIVATION}

In order to speed up talent training, Independent institute needs to improve the lab construction, which shall not only improve the lab hardware facilities, but also strengthen lab management, optimize lab resources allocation, and maximize the lab resource utilization.

\section{A. Optimize Resources Allocation and Improve Equipment Use Efficiency}

Main lab resources in colleges are mainly human resources and equipment, the people with different skills, when operating on the same equipment, can produce different experimental results, besides, the equipment use efficiency vary as well. Besides, some lab equipments are redundant, which are left used years in labs, however, those who need the equipment have no one, unable to complete the technical research and development. Therefore, it is necessary to optimize the human resources and equipment in labs so as to make full use of resources, improve the equipment use efficiency and further provide wide service for local economy.

\section{B. Strengthen the Lab Construction and Cultivate Suitable Talents for Local Development}

What for the local innovation driven development needs urgently are high-quality talents. The labs take an important mission to cultivate hi-tech development talents. During the lab construction and improvement, we should firmly combine the industrial restructuring with the demands for talents, focus on cultivating students' awareness in scientific innovation and humanity and cultivate more professional talents for the local economic development.

\section{Reinforce the Talent Cultivation and Improve the Awareness of Service and Development}

Independent institutes undertake an important mission to cultivate applied quality talents for the local economic construction and social development. During the talent cultivation, it should reinforce its awareness of serving the local economic development, greatly promoting preferential policies of local authorities, encourage college students in innovation and startup, improve the technical innovation strength and drive the technical development.

\section{CONCLUSION}

In short, there is still a long way to go for independent institutes to cultivate talents and service the local economic development. Independent institutes have to expand views and opening up and meet the needs of talent cultivation, relying on the "Introduce more and market itself" mode, deeply integrate colleges and the local, build a joint way between colleges and authorities, and colleges and enterprises, fully exerting the roles of college experimental resources in regional innovation driven development.

\section{REFERENCES}

[1] Hong Jiafen. Project Management-based Lab Construction in Independent Institutes $[\mathrm{J}]$. Laboratory Research and Exploration, 2015.32 (1): 162-164

[2] Wang Zhi, Du Yunhai, Liu Wenwen. Discussion Lab Construction in Colleges from Students' Startup [J]. Laboratory Research and Exploration, 2013,32(6): 287-289.

[3] Chen Weide. Construction and Research on Labs in Independent Institutes [J]. Experimental Technology and Management, 2010,27(12) 218-220.

[4] Wu Yujian. Dilemma and Ways for Innovation and Startup Education in Colleges [J]. Education Exploration, 2015, (11): 63-66.

[5] Ou Yanfei, Luo Jianliang, Chen Xiaolan, Ben Yi, Zhao Kaige, Pang Dongmei, Zhou Yiqin, Zhang Yong. Roles of Lab Qualification Certification Systems in Construction of Lab Talent Team in Colleges [J]. Experimental Technology and Management, 2013.30 (3): 175-179.

[6] Zhao Yulan, Liu Xin. Study on Innovation, Startup and Education Talents Cultivation System in Independent Institutes [J]. Educational Theory Exploration, 2014. (14): 3-4.

[7] Huang Xinghai. Discussion on Innovation, Startup and Education Practice Teaching Mechanism in Colleges [J]. Heilongjiang Researches on Higher Education, 2015. (11): 122-124. 